\title{
POSSIBILIDADE DO USO DE ALGUNS CONCEITOS DE TIPOS FUNCIONAIS DE PLANTAS NA AGROECOLOGIA: O CASO DO ASSENTAMENTO CHICO MENDES - POMBOS - PE ${ }^{1}$
}

\author{
Robson Soares Brasileiro²
}

\begin{abstract}
RESUMO
No presente estudo, procura-se associar alguns conceitos e parâmetros de Tipos Funcionais de Plantas (TFPs) em uma análise comparativa entre duas propriedades de agricultura familiar, sendo uma sob o sistema agroecológico de produção e outra sob o sistema convencional. Esse tipo de análise procura alguns atributos dos TFPs que ofereçam respostas comuns a perturbação, intensidade e fertilidade das propriedades pesquisadas. É importante compreender a relação entre as atividades agrícolas desenvolvidas nas propriedades, a relação que estas mantêm com as comunidades de plantas existentes na localidade e o grau de perturbação para a biodiversidade em cada área estuda. Os TFPs podem oferecer maiores indicadores da intensidade dos efeitos da atividade agrícola na propriedade quando levado em consideração os principais componentes das áreas, ou seja, solo, minerais, micro-organismos, matéria orgânica, insetos, plantas, animais, homem, recursos hídricos, topografia, dentre outros parâmetros.
\end{abstract}

Palavras-chave: Agroecologia, Tipos Funcionais de Plantas, Agricultura Familiar, Biodiversidade.

\begin{abstract}
In this study, we associate certain concepts and parameters of functional types of plants in a comparative analysis between two properties of family farming, one under the system of production and agroecology another under the conventional system. This type of analysis seeks some attributes of TFPs offering joint responses to disturbance, intensity and fertility of

\footnotetext{
${ }^{1}$ O presente artigo é parte de um capítulo da Dissertação de Mestrado com algumas reflexões sobre conceitos e aplicações de Tipos Funcionais de Plantas adquiridos durante as disciplinas: TEGF (Tópicos Especiais em Geografia Física): Tipos Funcionais Vegetais e Paisagens I: Conceitos, Classificação e Indicadores TEGF (Tópicos Especiais em Geografia Física): Tipos Funcionais Vegetais e Paisagens II: Aplicações.

${ }^{2}$ Doutorando do Programa de Pós-Graduação em Geografia da Universidade Federal de Pernambuco - UFPE e Bolsista da Fundação de Amparo à Ciência e Tecnologia do Estado de Pernambuco - FACEPE. robsonbrasileiro@gmail.com
} 
the properties searched. It is important to understand the relationship between agricultural activities developed in the properties, the relationship they have with the communities of plants in the locality and the degree of disruption to biodiversity each area studied. The TFPs can offer increased indicators of the intensity of the effects of agricultural activity in the property when taken into account the main components of areas, namely, soil, minerals, microorganisms, organic matter, insects, plants, animals, humans, water resources, topography, among other parameters.

Key words: Agroecology, Functional Types of Plants, Family Agriculture, Biodiversity.

\section{Introdução}

No atual sistema de produção agrícola mundial predomina a prática de cultivos de diversos gêneros alimentícios utilizando o sistema convencional de produção. Esse sistema é intensivo em capital, tecnologia e mão-de-obra. É importante frisar que essa prática agrícola é na maioria das vezes responsável por inúmeros impactos ambientais, tais como: erosão, contaminação dos recursos hídricos, exploração de mão-de-obra não qualificada, desertificação de algumas áreas, insegurança alimentar, dentre outros fatores sócio-ambientais e econômicos.

Em contrapartida, tem-se o sistema de produção agroecológica, o qual se constitui em um novo paradigma que propõe práticas de agricultura menos agressivas ao meio ambiente, promovendo a inclusão social e proporcionando melhores condições econômicas aos agricultores. Neste sentido, são comuns as interpretações que vinculam a agroecologia a uma concepção mais harmoniosa do ser humano com a natureza.

As bases científicas da agricultura alternativa referem-se à preservação ambiental, porém incorporam outros elementos mais amplos como à promoção sócio-econômica de agricultores que vivem em situação precária, proporcionando a eles uma visão política diferenciada, fazendo-os reconhecer seu papel na sociedade. A agroecologia defende uma relação muito estreita entre homem e natureza, beneficiando os aspectos ecológicos, econômicos, sociais e culturais.

Em Pernambuco, esse tipo de trabalho pode ser exemplificado através da ação de

ONGs como: SABIÁ (Centro de Desenvolvimento Agroecológico) e a Associação CAATINGA e Organizações da Sociedade Civil de Interesse Público (OSCIP) neste caso o Serviço de Tecnologia Alternativa (SERTA), a Associação Amigos do Meio Ambiente em 
Gravatá e muitas outras, seja na Mata Pernambucana, no Agreste ou no Sertão. Além disso, existem várias experiências agroecológicas em assentamentos e comunidades rurais pelo interior do Estado. Uma dessas experiências pode ser comprovada no assentamento Chico Mendes onde se desenvolve um projeto de agricultura familiar orgânica, inserindo ex-agricultores sem terra em um processo de reintegração com o meio rural.

O objetivo da pesquisa foi utilizar alguns conceitos e parâmetros de Tipos Funcionais de Plantas (TFPs) dentro da perspectiva do cultivo de hortaliças orgânicas em duas propriedades de agricultura familiar no Assentamento Chico Mendes: A primeira propriedade analisada desenvolve um sistema de agricultura familiar utilizando-se técnicas convencionais de cultivo. $\mathrm{Na}$ segunda propriedade os agricultores familiares trabalham sob o manejo agroecológico de produção.

Para o desenvolvimento da pesquisa adotaram-se alguns conceitos e parâmetros sobre Tipos Funcionais de Plantas adquiridos durante as disciplinas: TEGF (Tópicos Especiais em Geografia Física): Tipos Funcionais de Vegetais e Paisagens I: Conceitos, Classificação e Indicadores TEGF (Tópicos Especiais em Geografia Física): Tipos Funcionais de Vegetais e Paisagens II: Aplicações.

Dentro desse contexto conceitual foram selecionados alguns parâmetros de acordo com a morfologia e característica edafico-climática da área em estudo para melhor compreender o desenvolvimento do cultivo de hortaliças orgânicas e convencionais em pequenas propriedades familiares. Dentre os principais parâmetros utilizados para analise estão: tipos de vegetais da localidade, potencial hídrico, clima, solo, possíveis ações antrópicas, relevo, dentre outros fatores observados durante o decorrer do trabalho.

\section{Algumas características da área pesquisada}

O Engenho Ronda, atualmente denominado assentamento Chico Mendes, pertencia a antigos produtores de cana-de-açúcar no município de Pombos. Historicamente este engenho faz parte de um conjunto de propriedades situadas no sudeste de Pombos e oeste de Vitória de Santo Antão, cuja vocação era para a agroindústria canavieira.

O Assentamento possui uma área total de 1.758 hectares dos quais 1.246 são destinados às atividades agropecuárias e moradia para 90 famílias e 512 hectares de mata atlântica são destinados à preservação. A conservação dessa área de floresta traz grandes benefícios ambientais para os assentados, pois guarda a nascente do rio Pirapama e garante os recursos hídricos para o assentamento e, ao mesmo tempo, protege a fauna e flora da região.

A manutenção da área verde é tida como um incentivo para a produção orgânica, sendo vista como uma iniciativa pioneira entre os assentamentos de reforma agrária, 
projetando o município de Pombos no quadro pernambucano em termos de atividades agroecológicas.

Neste contexto de agricultura agroecológica, o assentamento Chico Mendes é visto como um núcleo de conservação ambiental. Pois os fatores históricos, a sua peculiar posição geográfica dentro do estado de Pernambuco e seus sítios montanhosos, resistem aos desgastes maiores, ao contrário de áreas vizinhas que são fortemente afetadas por vários impactos ambientais, notadamente o intenso desmatamento.

O assentamento é bastante diversificado em relação às potencialidades naturais, pois, além de possuir uma área de 512 hectares de mata atlântica relativamente preservada, guarda certa abundância em relação aos recursos hídricos. Às margens dessa reserva de mata atlântica nasce o rio Pirapama e o rio Canhas (afluente do rio Tapacurá e este por sua vez afluente do Capibaribe); além disso, o próprio assentamento é cortado por afluentes de outros rios tais como: rio Itapecirica, que desagua no rio Tapacurá, rio Água Azul e os riachos perenes São João Novo e Pau Amarelo.

O município insere-se em três Unidades de Paisagem: as Encostas Orientais do Planalto da Borborema, as Encostas Setentrionais do Planalto da Borborema, tendo em seu território algumas elevações que constituem os primeiros degraus deste maciço e o Planalto Litorâneo Rebaixado. Sua cobertura vegetal predominante é do tipo caatinga hipoxerófila, mas há áreas expressivas de florestas úmidas ou sub-úmidas devido às características geomorfológicas do município. Assim, Pombos possui duas áreas distintas: uma mais úmida, situada na porção sul e outra seca localizada ao norte (PROMATA, 2003, p. 29-30 apud BRASILEIRO, 2006, p. 62). Observe-se no mapa 01 as principais bacias hidrográficas no município de Pombos e a privilegiada posição geográfica do assentamento em relação a estas bacias hidrográficas. 


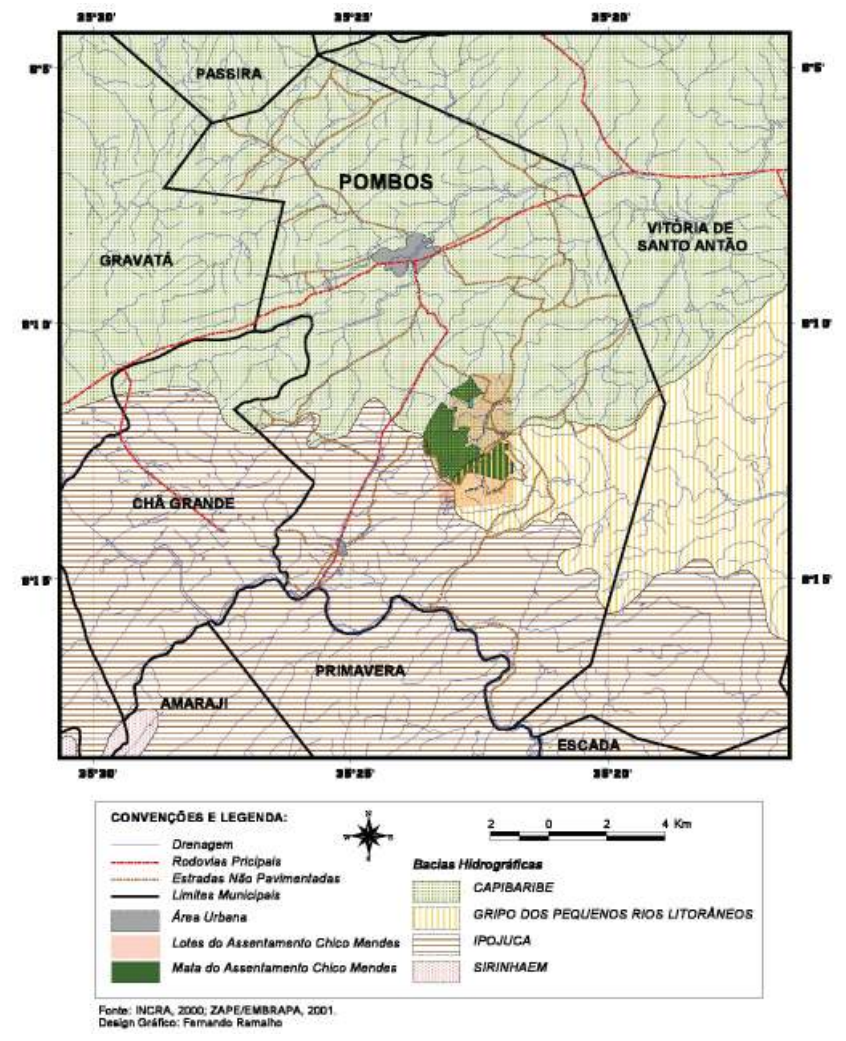

Mapa 01 - Bacias Hidrográficas no Município de Pombos - PE.

Estas especificidades contribuem para a boa oferta hídrica nesta porção do município (Sul e Sudoeste), como também contribui de forma decisiva para a prática da agricultura orgânica, servindo como potencialidade para o assentamento. Os solos são propícios para a prática do cultivo orgânico e, a regularidade das condições pluviométricas colaboram bastante para o desenvolvimento desse tipo de agricultura entre os assentados.

O assentamento, sob o ponto de vista edáfico-climático, possui todos os pré-requisitos para o desenvolvimento da agricultura orgânica: boa fertilidade do solo, abundância de recursos hídricos, matéria orgânica suficiente dentre outras qualidades. Muito embora a área do assentamento tenha sido parcialmente cultivada durante vários anos com a monocultura da cana-de-açúcar convencional. A área onde hoje se localiza o referido assentamento foi desapropriada em 1998 para o processo de reforma agrária, donde já se conta mais de uma década de conservação.

\section{A utilização de conceitos sobre Tipos Funcionais de Plantas na agricultura orgânica}

A agricultura é normalmente vista como consistindo de três tipos de sistemas: econômico, social e ecológico. Os três são interligados, e as interações entre a agricultura e o ambiente são complexas. Problemas ambientais como a degradação dos solos, desertificação, 
destruição das florestas tropicais e conseqüente diminuição da vida selvagem e poluição de mananciais hídricos estão relacionados com práticas agrícolas inadequadas ou com o uso intensivo de insumos. Ao mesmo tempo, a agricultura está sob a influência direta destes mesmos problemas, além de outros para os quais não contribui diretamente, como o aquecimento global, mudanças climáticas, destruição da camada de ozônio, poluição do ar e chuva ácida.

Contudo, a agricultura também pode desempenhar funções diretas importantes no encaminhamento de soluções para problemas ambientais em escala global, regional e local, na medida em que envolva mecanismos de controle e conservação de recursos ambientais. Além disso, pode contribuir, também, de maneira indireta ao demandar o desenvolvimento e a adaptação de tecnologias ambientais.

Mediante o contexto acima apresentado observou-se que o desenvolvimento da agricultura orgânica no referido assentamento pode ter maior desempenho quando utilizado alguns conceitos e parâmetros sobre Tipos Funcionais de Plantas para melhor entender as complexidades físicas da localidade. Assim, as unidades de paisagens das duas propriedades analisadas se caracterizam por dinâmicas de elementos geográficos diferenciados que irão determinar a correlação de dados ambientais. Segundo Bertrand, 1968 apud Bohrer, 2000, p. 109:

\begin{abstract}
Uma unidade de paisagem pode ser considerada como "uma porção do espaço caracterizada por um tipo de combinação dinâmica de elementos geográficos diferenciados físicos, biológicos e antrópicos, que ao enfrentarem-se dialeticamente uns com os outros, fazem da paisagem um 'conjunto geográfico' indissociável que evolui em conjunto, tanto sob o efeito de interações entre os elementos que a constituem como da dinâmica própria de cada um dos elementos individuais".
\end{abstract}

Nesse caso alguns parâmetros adotados para utilização dos Tipos Funcionais de Plantas em ambas as propriedades foram usados para identificar fatores e condicionantes que atribuíram um determinado grau de desempenho das práticas de cultivo utilizadas nas duas propriedades familiares em estudo. Antes de entrar nos pormenores da pesquisa dissertaremos sobre alguns conceitos de Tipos Funcionais de Plantas adotados por pesquisadores.

Falar de TFPs dentro de uma abordagem geográfica não é tarefa fácil, ainda mais quando se pretende utilizar conceitos tão novos dentro de uma perspectiva agroecológica de agricultura familiar. Porém, a interdisciplinaridade é de extrema importância para o desenvolvimento e bom andamento de algumas pesquisas, pois além de trazer novas idéias e possibilidades de avanços colabora também para a melhor compreensão do objeto em estudo. Veremos abaixo alguns conceitos fundamentais sobre Tipos Funcionais de Plantas. 
Interessante observar que os autores têm definições bem semelhantes, ou seja, chegando a conclusão que os TFPs são grupos que apresentam respostas similares as condições ambientais.

Um TFP é considerado como um agrupamento de planta que cumpre uma função similar no ecossistema. Este grupo é caracterizado por um ou mais atributos funcionais comuns e podem ser classificados como grupo de respostas ou grupos de efeitos (DIAZ \& CABIDO, 1997; LAVOREL \& GARNIER, 2002 apud SOSINSK, 2005, p. 10).

Neste estudo, os Tipos Funcionais de Plantas são observados como grupos de algumas espécies que apresentam características para o desenvolvimento de uma agricultura de base agroecológico em pequenas propriedades. As características ambientais da localidade estudada são bastante diversificadas e as relações entre a paisagem agrícola de uma propriedade agroecologica e outra sob sistema de cultivo tradicional apresentam uma enorme diversidade de espécies de plantas nas áreas de cultivo. Percebe-se que na propriedade sob o sistema agroecológico de cultivo o número de espécies de Tipos Funcionais de Plantas é bem maior em relação a propriedade convencional. Mais adiante explicarei melhor o porquê da diferenciação na quantidade de TFPs nas propriedades.

Segundo alguns autores, os TFPs são grupos de plantas que exibem respostas similares às condições de ambiente e apresentam efeitos parecidos sobre os processos dominantes do ecossistema. Tipos Funcionais de Plantas são os funcionalmente similares, ou seja, aqueles que permitem a percepção mais nítida da associação entre vegetação e ambiente (PILLAR, 1999 apud SOSINSK \& PILLAR, 2004, p. 2). Definição semelhante é observada na citação abaixo:

Plant functional types (PFTs) are defined as groups of plant species with similar plant traits and similar realized niches with respect to multiple environmental factors (SKARPE 1996; LAVOREL et al. 1997 apud KLEYER, 2002, p. 167).

Como o referido estudo é uma análise comparativa entre duas propriedades agrícolas, nesse caso, é importante explicar a diversidade em espécies das comunidades locais, porém temos que levar em consideração a escala espacial das áreas selecionadas para a pesquisa como o número de parâmetros adotados para este estudo. As propriedades selecionadas para esta pesquisa são como já mencionadas, propriedades familiares possuindo entre 10 a 15 hectares de extensão. Alguns dos principais parâmetros adotados para a observação da pesquisa foi o porte das comunidades vegetais próximas às áreas de cultivos, a topografia do terreno, a disponibilidade de recursos hídricos, a relação do agricultor com a natureza, e os principais impactos gerados pelas atividades agrícolas nas duas propriedades. 
Este tipo de abordagem baseada na definição de atributos, os quais permitem a definição de tipos funcionais, constitui-se uma ferramenta que permite melhor entendimento da dinâmica da vegetação por fornecer menor número de descritores da vegetação. (SANTOS, et. al. 2006, p. 1902 -1903).

Existem inúmeros atributos que podem ser utilizados para a definição de Tipos Funcionais. Os atributos mais relevantes são expressões observáveis de formas ou comportamentos associados, quanto à ocorrência ou performance dos organismos, a alterações em variáveis ecológicas (PILLAR 1999 apud PILLAR, 2007, p. 1).

Seguindo a linha dos demais autores citados para os conceitos de TFPs Blanco (2004) afirma que o estudo da relação funcional das formas vegetais com o ambiente é desenvolvido desde meados do século XIX, envolvendo diversos parâmetros de avaliação dentre eles tipos fisionômicos e formas de vida (BLANCO, 2004, p. 1).

Tomando como referência a citação acima percebe-se o quanto é importante à definição dos parâmetros adotados para o estudo de TFPs, principalmente quando se trata de escalas pequenas, pois a boa delimitação da área para o estudo e, os parâmetros a serem observados dentro da mesma proporcionará uma maior precisão no momento da análise dos dados observados.

\section{Agricultura familiar e agroecologia}

Antes de começar a dissertar sobre as pequenas propriedades analisadas, acho conveniente situar o leitor sobre algumas definições de agricultura familiar ou propriedade familiar, pois o esclarecimento deste sistema de produção ajudará mais a frente o leitor na compreensão de alguns conceitos abordados neste artigo e, até mesmo na própria compreensão sobre o objetivo do referido estudo. É importante ressaltar que as definições sobre agricultura familiar são bastante diversificadas entre os estudiosos da referida temática, porém selecionamos algumas que estão mais relacionadas ao presente estudo.

Entretanto ressaltamos que a prática agrícola em geral causa sérios danos ao meio ambiente, contudo o grau de impactos das atividades agrícolas familiar é bem menor em relação aos grandes monocultivos. Como bem esclarece MA (2006), os impactos da agricultura tornam-se acelerados principalmente a partir da Revolução Verde, período no qual se intensifica o uso de agroquímicos na agricultura, pautado no discurso de erradicação da fome no mundo:

Over the last 50 years, however, agricultural intensification and extension have revolutionized rural regions around the world; thousands of hectares of natural habitats have been removed, pesticide use has sky rocketed, and much of the 
landscape is dominated by monoculture. One of the most dramatic impacts has been the depletion of wildlife biodiversity on farmland (RUTTAN 1994, SRIVASTAVA et al. 1998, PITKÄNEN \& TIAINEN 2001). Protecting, restoring, and expanding habitats and buffering water bodies in agricultural ecosystems have now become a top priority for land owners, conservationists, policy makers, and others (MA, 2006, p. 10).

Segundo Brasil (2004), há uma idéia predominante de que agricultura familiar é um conceito genérico, recentemente aceito como termo hegemônico, e que representa um modo específico de produzir e de conviver em sociedade, daqueles que simultaneamente reúnem sob o domínio da família, em seu espaço produtivo, o trabalho e os meios de produção. A autora esclarece que:

O ponto de partida é o conceito de agricultura familiar, entendida como aquela em que a família, ao mesmo tempo em que é proprietária dos meios de produção assume o trabalho no estabelecimento produtivo. É importante insistir que esse caráter familiar não é um mero detalhe superficial e descritivo, ou seja, o fato de uma estrutura produtiva associar família - produção-trabalho tem conseqüências fundamentais para a forma como ela age econômica e socialmente. No entanto, assim definida, essa categoria é necessariamente genérica, pois a combinação entre propriedade e trabalho assume, no tempo e no espaço, uma grande diversidade de formas sociais (WANDERLEY, 1999, p. 23 apud BRASIL, 2004, p. 72).

Hoje em dia, diante dos inúmeros impactos ambientais causados por diversas ações, seja natural ou antrópica, várias esferas da sociedade estão buscando alternativas de produção e convívio mais harmoniosos e equilibrados com o meio ambiente. Diante dos processos de degradação da natureza, sejam eles antrópicos ou provocados por fenômenos naturais, cabe ao agricultor conhecer cada vez mais os limites e os sinais da natureza, ficando atento aos desequilíbrios e corrigi-los, pois na perspectiva da agroecologia deve-se eliminar a causa do problema e não apenas suas conseqüências (BRASILEIRO, 2006, p. 25).

A prática da agricultura familiar vem incorporando ações e manejo que são menos impactantes ao meio ambiente. Nesse caso a prática da agroecologia no sistema de produção familiar tem apresentado bons resultados.

\section{Análise das propriedades pesquisadas}




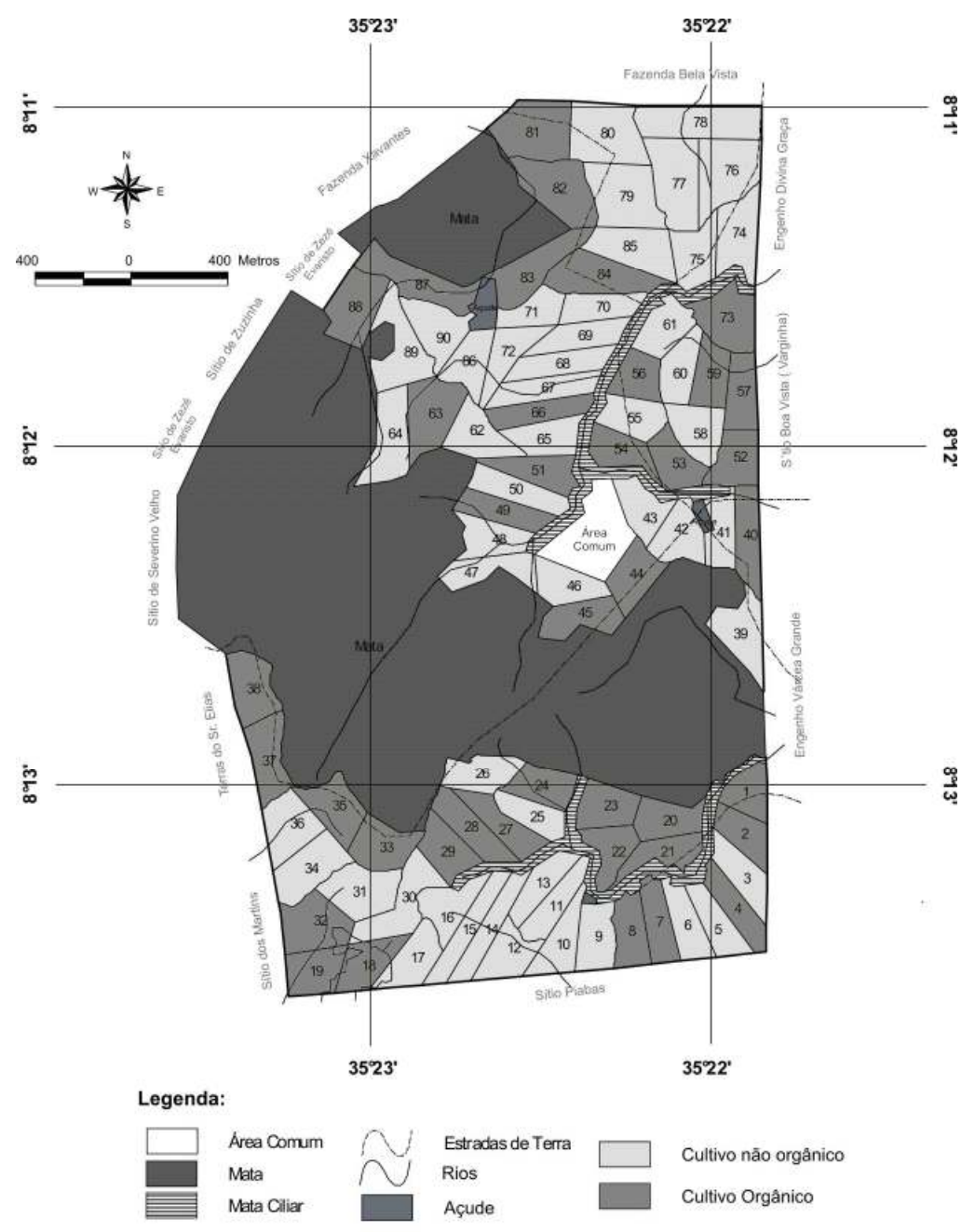

Mapa 02 - Propriedades Familiares no Assentamento Chico Mendes

A primeira propriedade familiar observada tem seu sistema de cultivo sob o manejo agroecológico ou práticas agroecológicas de produção. Neste tipo de manejo da propriedade o agricultor utiliza técnicas alternativas menos nociva a biodiversidade existente em sua propriedade. Tomando como base os parâmetros adotados para a identificação dos TFPs nas propriedades familiares, ressaltando que estes parâmetros já foram definidos no decorrer do texto, então cabe agora apresentar as características dos TFPs observadas nas propriedades.

$\mathrm{Na}$ propriedade sobe o manejo de produção agroecológica foi observado TFPs que apresentam as seguintes características: lenhosas, habito (erva), (arbustos) e (árvores), aquisição de nutriente, além de apresentarem algumas gramíneas, leguminosas e herbáceas.

As leguminosas têm uma grande importância no sistema agroecológico, pois elas possuem colônias de bactérias (rizobuim) nas raízes que ajudam a absolver o nitrogênio atmosférico transformando-o em nitrato no solo, deixando-o mais fértil. 
A propriedade pesquisada sob o sistema agroecológico de produção familiar foi a de número (23), no mapa 02 observa-se que este lote fica nos limites da área de Mata Atlântica e próxima a nascente do rio Pirapama que existe dentro do assentamento. Nesse caso, os tipos funcionais presentes nesta localidade, além de contribuir para a boa prática do desenvolvimento da agroecologia proporciona também a preservação da nascente do referido rio.

Os TFPs encontrados nesta mata possuem características que contribuem para boa umidade do solo e fertilidade, como também depositam através das folhas uma espessa camada de matéria orgânica que vai sendo decomposta aos poucos. Esses detalhes fazem dessa localidade uma área privilegiada e com condições perfeitas para o manejo agroecológico, sem deixar de mencionar a importância desse sistema de cultivo para boa disponibilidade dos recursos hídricos dentro do assentamento.

Nesse caso a compreensão de como o agricultor utiliza os potencias naturais para a boa prática agrícola ajuda a entender melhor os métodos alternativos no sistema de produção familiar. Segundo MA, (2008) é de grande importância à interpretação da utilização das terras agrícolas e suas escalas para manutenção da biodiversidade.

\footnotetext{
Understanding the role of agricultural land use in maintaining the biodiversity of semi-natural habitats is important in moving toward sustainable agriculture (Mason 2003). At the same time, scale is an important concept in integrating the structural configuration of land use and ecological process of biodiversity in agricultural landscapes (WU et al. 2002 apud MA, 2008, p. 269).
}

The sustainable development of agriculture depends on a diversity of organisms and ecosystems in landscapes. Maintaining and promoting the diversity of wild species on farmland is one of the most important long-term aims of sustainable agriculture (Mason 2003 apud MA, 2006, p. 9). Dentro desse contexto a prática da agroecologia familiar levando-se em consideração os TFPs na localidade pode ajudar o agricultor a interpretar melhor os sinais da natureza ao desenvolver determinada atividade agrícola.

A referida propriedade estuda (23) esta localiza em uma área estratégica em termos de recursos naturais tais como vegetação e recursos hídricos. A vegetação pode ser usada ainda para indicar fatores não-mensuráveis ou não mapeáveis, determinando-se empiricamente a correlação de dados ambientais com as comunidades vegetais ou tipos de vegetação, ou interpretando a estrutura da vegetação e das plantas individuais (formas de vida ou tipos funcionais) em termos de adaptação ao clima ou a padrões edáficos/hidrológicos (SALAS, 1987; ZONNEVELD \& SURASANA, 1988 apud BOHRER, 2000, p. 110). Observe-se nas fotos (01 e 02) alguns dos potenciais naturais da propriedade estudada. 
Os TFPs nesta localidade, além de formarem comunidades de plantas que ajudam a manter os bons condicionantes para o manejo agroecológico da propriedade, permitem também que os tipos funcionais lenhosos e de maior porte ofereçam sombreamento durante maior parte do dia graças a sua arquitetura, servem como quebra vento impedindo que os ventos fortes prejudiquem as plantações de hortaliças orgânicas e, os tipos funcionais com folhas mais espessas minimizam o impacto da gotícula de chuva no solo, evitando possíveis processos de erosão.

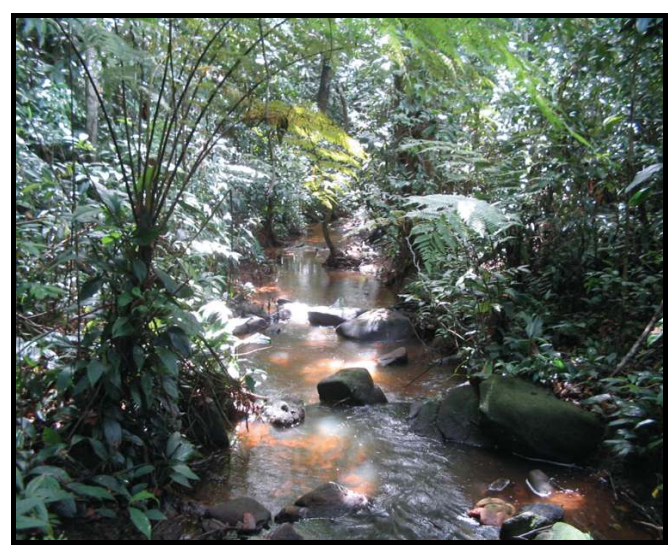

Foto 01 Rio Pirapama (Mata de Ronda), 27/05/2005

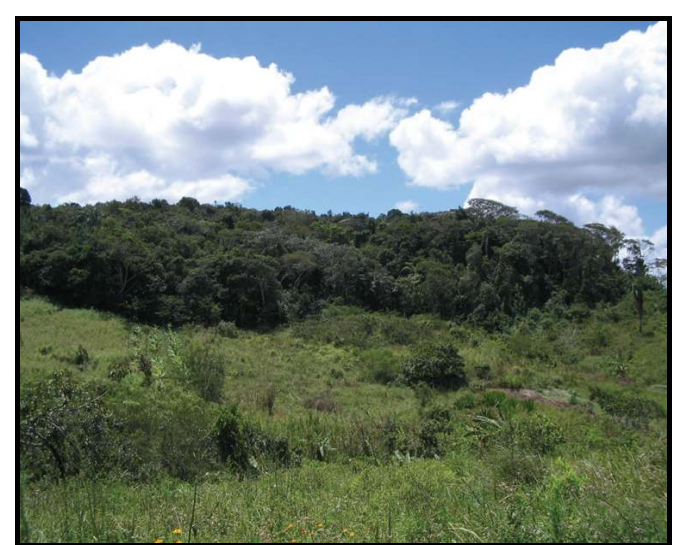

Foto 02 Mata de Ronda, 25/08/2004 (Fotos do autor)

Além dos fatores já citados é interessante ressalta que a relação de equilíbrio que o proprietário mantém com a natureza é extremamente importe para o uso sustentável dos recursos. Nessa propriedade a única atividade econômica desenvolvida com base no manejo agroecológico é o cultivo de hortaliças orgânicas. Ao contrário de outras propriedades sob o cultivo tradicional que além de cultivar a terra se dedicam também ao criatório de animais.

Os lotes agroecológicos dentro do assentamento ajudam a preservar os TFPs da localidade, mas vale mencionar, que praticamente todo o assentamento faz limite com propriedade de monocultura de cana-de-açúcar. O uso sustentável de alguns recursos naturais não depende única e exclusivamente das ações locais, mas também das ações regionais e de tudo que esteja acontecendo a sua volta. Segundo MA (2006) a preservação e equilíbrio de algumas espécies da flora e da fauna dependem das paisagens circundantes.

Human activities and land management have been strongly affecting the availability of habitats for species (NAVEH \& LIEBERMAN 1984, FORMAN 1995). Though habitat quality may be the most important factor determining the presence of a species at a given site (DUELLI 1997), species diversity within a patch additionally depends on the structure of the surrounding landscape (FARINA, 1998). Conservation strategies now frequently consider not only that the habitat must be retained, but also that the surrounding landscape context that influences the habitat across the landscape of concern (SHUMAKER 1996). Some studies demonstrated that species richness was closely linked with the composition of a landscape on a 
regional scale (DUNNING et al., 1992, DALE et al. 2000, WAGNER et al. 2000). In human disturbed agricultural landscapes, the landscape context has a huge influence on wild species diversity in semi-natural habitats in the landscape (MA, MAOHUA, 2006, p. 16 e 17).

A diversidade de espécies vegetais existentes na mata é outra potencialidade dentro do assentamento, principalmente para os lotes que fazem limites com a mesma. Nas bordas da mata predomina os lotes sob o sistema agroecológico de produção familiar e o sistema convencional. $\mathrm{O}$ ideal é que as propriedades convencionais que fazem limites com a área de mata se convertam em sistemas agroecológicos, assim, protegerá melhor as espécies vegetais existentes como também os recursos hídricos.

A descrição de comunidades vegetais, relacionando formas com o ambiente baseia-se na observação de que fatores físicos e biológicos do meio são determinantes da fisionomia da vegetação. $\mathrm{O}$ ambiente funciona como um filtro, removendo os indivíduos que não apresentam determinada adaptação (KEDDY, 1992 apud SOSINSK \& PILLAR, 2004, p. 1). If comparable patterns emerge, some kind of generality can be assumed. However, hardly any two landscapes can be expected to be identical with respect to all environmental factors. Environmental differences should be reflected in PFTs that are unique to each of these landscapes (KLEYER, 2002, p. 167).

A segunda propriedade pesquisa apresenta características bem diferentes da primeira, apesar de ser também uma propriedade de agricultores familiares, porém o sistema de cultivo implantado na mesma não é agroecológico, mas sim, agricultura convencional, isto é, com o uso de insumos externos, tipo: herbicidas, pesticidas e fertilizantes, além do uso de algumas máquinas e sistemas de irrigação ineficientes.

Esta propriedade é a de número (77) ver mapa 02. Esse lote fica mais afastado da área de mata, por isso apresenta algumas características bem diferenciadas da primeira propriedade pesquisada. Porém, o importante é que observou-se que os Tipos Funcionais de Plantas nessa área são bem diferentes, a predominância é de algumas comunidades de gramíneas e arbustos, esse detalhe torna esse lote praticamente inviável para o sistema agroecológico de produção familiar.

A topografia nessa localidade é bastante irregular, havendo alternância de áreas de morro, planas e algumas praticamente inviáveis para cultivo e pasto de animais. Além do mais, a disponibilidade de recursos hídricos não é tão boa quanto na primeira propriedade estudada, isso dificulta a umidade e o desenvolvimento de algumas comunidades de TFPs. Outro detalhe importante para os TFPs é que nesse lote o agricultor familiar cria alguns 
bovinos. Tal prática é desenvolvida na propriedade de maneira bastante irregular, isto é, não existe uma alternância de locais para os animais pastarem, o que provoca sérios impactos ao meio ambiente através de compactação do solo.

Os impactos diretos sobre a vegetação através do ato de pastar ou movimentar-se do herbívoro causam um efeito imediato na estrutura física da vegetação, mudando a arquitetura das plantas (DIAZ et al, 1992; SOSINSK \& PILLAR, 2004, apud SOSINSK, 2005, p. 18). Já os impactos indiretos alteram a comunidade de planta em um período mais longo, pela compactação do solo, afetando a disponibilidade de nutrientes, água e luz (MCINTYRE et. al., 1999 apud SOSINSK, 2005, p. 18). Conforme a freqüência e intensidade do pastejo pode haver colonização, aumento da riqueza de espécies, ou extinção local de espécies (GRIME, 1998; OLFF \& RITCHIE, 1998 apud SOSINSK, 2005, p. 18), alterando, portando, a diversidade de espécies na pastagem.

Sosinsk (2005) esclarece perfeitamente os efeitos do pastejo de herbívoros na propriedade. Pois para o autor os impactos não se limitam apenas nas comunidades de plantas, mas afeta também o solo e seus micro-organismos. Porém é interessante realizar uma interpretação mais aprofundada dos efeitos do pastejo em determinadas localidade, principalmente quando essa prática agropecuária não é feita com técnicas adequadas. $\mathrm{Na}$ propriedade em estudo, esse tipo de manejo dos animais além de provocar a extinção de algumas espécies vegetais e a compactação do solo, pode por sua, dar origem a um intenso processo de erosão, principalmente nas áreas mais íngremes ou de topografias acidentada dentro da propriedade.

Embora a referida propriedade não disponha de boas condições para o cultivo de hortaliças orgânicas, porém apresenta algumas áreas de faixa, isto é, paisagens predominantes em algumas áreas agrícolas. Geralmente se localiza entre as lavouras e alguns cursos d' água apresentando importantes funções para o desenvolvimento de uma agricultura sustentável, isso devido à função de proteger os recursos naturais. MA (2008), esclarece com maiores detalhes as funções das áreas de faixas na agricultura:

Buffer strips are a dominant habitat type in agricultural landscapes, and these lie between crop fields and water ways (rivers, main ditches, or channels). Buffer strips have important ecological functions for sustainable agriculture, such as reducing soil erosion, and acting as an agrochemical buffer for water protection, but buffer strips also provide refuges and movement corridors for farmland wildlife (DENNIS et al. 1994; JENSSEN et al. 1994; DANIELS \& GILLIAM 1996; LE COEUR et al. 1997; BUREL 1996; SPARKS et al. 1999 apud MA, 2008, p. 269). Plant diversity in these buffer strips is important for supporting these functions (MARSHALL et al. 1994; UUSI-KÄMPPÄ \& YLÄ-RANTA 1996 apud MA, 2008, p. 269). During recent decades, however, plant diversity in the semi-natural linear habitats has declined severely (KLEIJN 1996) because of the increase of more intensive agricultural land use (MERRIAM 1988; FORMAN 1995; DEFRIES 2004 apud MA, 2008, p. 269). 
Apesar da propriedade não oferece boas condições para o desenvolvimento da agricultura agroecológica, nota-se outro agravante, ou seja, a relação que o agricultor familiar assentado nesse lote mantém com a natureza. Diferentemente da propriedade agroecológica familiar na qual o agricultor se preocupa em minimizar os impactos das atividades agrícolas utilizando técnicas e alternativas de produção bem menos agressivas ao meio ambiente, o mesmo não acontece na segunda propriedade estuda, já que está sob o manejo da agricultura familiar convencional, pautada ainda em técnicas rudimentares e ineficientes em termos de produção e uso dos recursos ecologicamente corretos.

Nesse caso os impactos sob os TFPs são bem maiores, pois esse tipo de agricultura precisará sempre de novas áreas para o cultivo de agricultura de subsistência. Essa prática pode em longo prazo, colocar em processos de extinção algumas espécies vegetais que são de grande importância para o equilíbrio da flora e fauna da área do assentamento como um todo.

\section{Considerações finais}

A riqueza de espécies observadas na propriedade familiar sob o sistema de manejo agroecológico foi bem superior ao da propriedade sob o sistema de agricultura familiar convencional (uso de técnicas mais rudimentares ou impactantes ao meio ambiente). $\mathrm{Na}$ propriedade familiar convencional os impactos sob os TFPs são bem maiores, isso devido ao próprio manejo dos recursos e das práticas e das atividades econômicas desenvolvidas nessa localidade.

Nesse lote predomina a pluriatividade da agricultura, ou seja, a família se dedica a várias atividades econômicas dentro da propriedade ou fora dela. De certa forma, isso faz com que, o agricultor se dedique menos a sua propriedade, passe a não observar ou a ignorar os sinais da natureza, utilizando-se de produtos externos a propriedade (herbicidas, fertilizantes, pesticidas, etc.) para a correção dos desgastes do uso ineficientes dos recursos naturais da propriedade.

Dentro dessa perspectiva de análise da prática agroecológica de agricultura familiar, sob o enfoque de alguns conceitos de Tipos Funcionais de Plantas, fica claro que estes podem ser um forte indicador do equilíbrio dos recursos naturais disponíveis na propriedade. Em se tratando, de propriedades agrícolas, quanto mais comunidades de TFPs em uma determinada localidade, talvez menos vulnerável esta esteja a ações antrópicas desenvolvidas por algumas técnicas de agricultura ineficientes. 
Todavia, é bom deixar claro que para comprovação mais detalhada de tal afirmação, requer um estudo mais aprofundado que leve maior espaço de tempo, como também envolva outros parâmetros para a análise dos TFPs e englobem elementos externos as propriedades. Como para o momento o objetivo era realizar uma análise da agricultura agroecológica familiar integrada a alguns conceitos de TFPs, considera-se nesse caso, satisfatório os resultados atingidos.

\section{Referencias bibliográficas}

BLANCO, Carolina Casagrande. Reconstrução da dinâmica de curta duração em vegetação campestre sob pastejo, com base em tipos funcionais. 2004. 85p. Dissertação (Mestrado) - Instituto de Biociências, UFRGS - Porto Alegre.

BOHRER, Claudio Belmonte de Athayde. Vegetação, paisagem e o planejamento do uso da terra. GEOgraphia - Ano. II - No 4 - 2000, UFF.

BRASIL, Ida Claudia Pessoa. Estado, agricultura familiar e desenvolvimento sustentável: construção de uma relação diferenciada. 2004. 238p. Tese (Doutorado) - Universidade de Brasília. Centro de Desenvolvimento Sustentável. Brasília.

BRASILEIRO, Robson Soares. Agricultura orgânica e conservação ambiental: uma alternativa de fortalecimento da produção familiar no assentamento Chico Mendes em Pombos/PE. 2006. 157p. Dissertação (Mestrado). Universidade Federal de Pernambuco Departamento de Ciências Geográficas. Recife.

MA, MAOHUA. Plant species diversity of buffer zones in agricultural landscapes: in search of determinants from the local to regional scale. 2006. 41p. Dissertação (Mestrado) - Department of Applied Biology/University of Helsinki - Finland. 2006.

Multi-scale responses of plant species diversity in semi-natural buffer strips to agricultural landscapes Applied Vegetation Science 11: 269-278, 2008 doi: 10.3170/2008-718426, published online 21 February 2008 (C) IAVS; Opulus Press Uppsala.

PILLAR, Valério De Patta. Bases teóricas e metodológicas para utilização de tipos funcionais. Anais do VIII Congresso de Ecologia do Brasil, 23 a 28 de Setembro de 2007, Caxambu - MG.

SANTOS, Betina Raquel Cunha dos; SILVA, Marcelo Abreu da; MEDEIROS, Renato Borges de; BLANCO, Carolina; SOSINSK JÚNIOR, Enio Egon; PILLAR, Valério de Patta; SAIBRO, João Carlos de; RODRIGUES, Rodrigo Sasso. Interação comportamento de pastejo $\mathrm{X}$ dinâmica de tipos funcionais em pastagem natural na Depressão Central do Rio Grande do Sul. R. Bras. Zootec. v.35, n.5, p. 1897-1906, 2006.

SOSINSK JÚNIOR, Enio Egon. Modelos de simulação espacial de efeitos de pastejo em vegetação campestre. 2005. 125p. Tese (Doutorado) - Universidade Federal do Rio Grande do Sul, Porto Alegre. 
SOSINSKI JÚNIOR, Enio Egon \& PILLAR, Valério De Patta Respostas de tipos funcionais de plantas à intensidade de pastejo em vegetação campestre. Pesq. agropec. bras., Jan 2004, vol.39, no.1, p.1-9. ISSN 0100-204X. Revista Embrapa.

KLEYER, Michael. Validation of plant functional types across two contrasting landscapes. Journal of Vegetation Science 13: 167-178, 2002 (C) IAVS; Opulus Press Uppsala. 